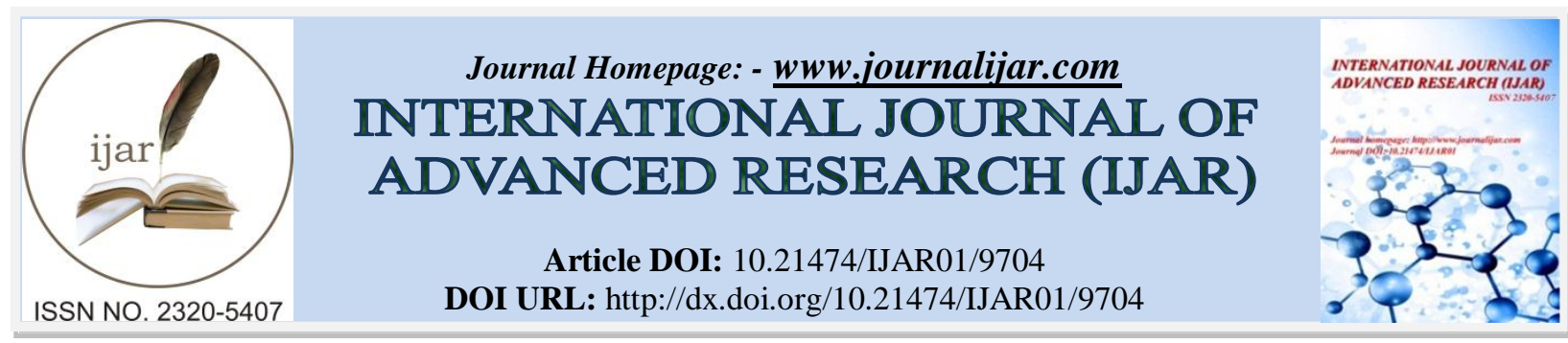

RESEARCH ARTICLE

\title{
OCCUPATIONAL RISK ASSESSMENT AND ABATEMENT OF HAZARDS AMONGST LOAD BEARERS OF KOLKATA.
}

\author{
Samanta Das ${ }^{1}$, Sugata Das ${ }^{2}$, Dr Anandi Bagchi ${ }^{3}$ and Dr Subrata Ghosh ${ }^{4}$. \\ 1. Research Scholar, Department of Physiology, Hooghly Mohsin College. Burdwan University. \\ 2. Research Scholar, Department of Physiology, University of Calcutta. \\ 3. Assistant Professor, Department of Physiology, Jhargram Raj College (Girls' Wing), Govt. of West Bengal. \\ 4. Professor, Department of Physiology, Hooghly Mohsin College. Govt. of West Bengal.
}

\section{Manuscript Info}

.........................

Manuscript History

Received: 08 July 2019

Final Accepted: 10 August 2019

Published: September 2019

Key words:-

MMH, Lifting Index, Job Strain Index, Intraocular pressure, Occupational hazards.

\section{Abstract}

Background: Manual Material Handling (MMH) is a component of many jobs and activity undertaken in life. MMH work contributes to a large percentage of a 1.1 million cases of musculoskeletal disorders reported annually in the India.

Objectives: To take correct measure of the strain, they experienced quantitatively, to apprehend the correlation between the carried load and its impact, to establish a relationship of weight carry with eyes\& to recommend some possible ways to abate hazards.

Materials and Methods: The study was a single-blind study conducted in Manual Load Bearers (MLB) of markets and Rail stations of Howrah, Hooghly and Kolkata, West Bengal. The sample comprised of 95 workers from markets and rail stations of different areas of West Bengal, India. All general physical parameters, physiological parameters, lifting parameters \& eye pressure were measured by standardised procedure.

Result: All the experimental workers showed raised level $(\mathrm{p}<0.05)$ of physiological, lifting and ocular pressure parameters.

Conclusion: Due to stressful job routine, manual load bearers faced different occupational hazards. Calculated JSI showed significantly higher values than NIOSH recommendation. Repetitively carry huge load on their head affects their ocular pressure. An elastic back support with head gear may reduce their occupational hazards.

Copy Right, IJAR, 2019,. All rights reserved.

\section{Introduction:-}

Manual Material Handling (MMH) is a component of many jobs and activities undertaken in life. Typically, it involves lifting, pulling, pushing and carrying objects by hand. Loading and unloading truces, cart, boxes or crates; moving parts or assemblies from one place to another, loading paper to the copier or picking binders from an overhead shelf, lifting patients from bed or transporting them in a wheelchair are typical MMH activities found in work setting. Manual materials handling operations are carried out in most workplaces. Each handling task poses unique demands on the worker. 
Any job that involves heavy labor or manual material handling may include a high risk for injury on the job. Manual material handling not only entails lifting, but also usually includes climbing, pushing, pulling, and pivoting, all of which pose the risk of injury to the back. MMH work contributes to a large percentage of a 1.1 million cases of musculoskeletal disorders reported annually in the India. Musculoskeletal disorders often involve strains and sprains to the lower back, shoulders and upper limbs. Potentially injurious tasks may involve bending and twisting, repetitive motions, carrying or lifting heavy loads and maintaining fixed positions for a long time. MMH under these conditions can lead to damaged muscles, tendons, ligaments, nerves and blood vessels. ${ }^{[1]}$

Work-related health problems are experienced by workers across all types of jobs and work sectors, and to many, it has become a fact of life. However, some types of work groups seem to be particularly at higher risk of these problems. Building construction and brick-making workers perform tedious and strenuous activities daily for long hours that lead to musculoskeletal pain/injury which affects diverse parts of the body. Musculoskeletal Disorders (MSDs) accounts for over 50\% of total work-related health problems experienced by workers across various work sectors (EUSOS 2002:108). Work-related Musculoskeletal Disorders (WMSDs) covers a wide range of inflammatory and degenerative diseases, and disorders that result in pain and functional impairment. ${ }^{[2]}$ According to previous literature the discomfort and pains may affect the body's soft tissues including damage to the tendon, tendon sheaths, muscles and nerves of the hands, wrists, elbows, shoulders, neck and back. These disorders, apart from leading to human sufferings, also have negative economic impacts as a result of decrease in working capacity and production output. It is also found that pain in the neck and shoulders often causes work disability among employees and are frequently associated with long periods of disability and sick leave. According to the World Health Organization WHO (1985), Work-related Musculoskeletal Disorders (WMSDs) arise when people are exposed to work activities and work conditions that significantly contribute to their development or exacerbation, though it may not be the sole determinant of causation. Gerr et al (1991) pointed out that these disorders have been found to be associated with numerous occupational 'risk factors', including physical workload factors such as force, posture, manual handling, repetitive work and vibration, as well as individual factors. These factors become harmful because of repetitive activities often in a laborious and awkward manner without adequate rest and recovery ${ }^{[3]}$ Commenting on the need for interest in ergonomics, WHO (1998) explained that the increase in concerns for ergonomic issues in the workplace is well founded; as it is related to work/machine interaction, workstation design, working position; the suitability of instruments to the physical and physiological characteristics of the workers, psychological factors and environmental conditions (heat, cold, noise, air pollution) which may affect workplaces (workstations) and affect the health of the workers. Ajimotokan (2008) pointed out that ergonomic improvement tends to lower the physical demands of work tasks, thereby lowering the incidence and severity of the musculoskeletal injuries. ${ }^{[4]} \mathrm{A}$ relatively small decrease in intraocular pressure (IOP) is related to sub-maximal work. Decreases of intraocular pressure (IOP) are inversely proportional to the workload. Prolonged weightlifting could be a potential risk factor for the development or progression of glaucoma. Intermittent IOP increases during weightlifting should be suspected in patients with normal-tension glaucoma who perform such exercises. ${ }^{[5]}$

The purpose of this study was to determine

1. To take correct measure of the strain, they experienced quantitatively.

2. To apprehend the correlation between the carried load and its impact.

3. To establish a relationship of weight carriage with eyes.

4. To recommend some possible ways to abate hazards.

\section{Material and Methods:-}

The study was a single-blind study conducted on Manual Load Bearers (MLB) of markets and rail stations of Howrah, Hooghly and Kolkata.

\section{Study Sample:-}

The MLB were randomly selected for the study. Thus, the sample comprised of 95 workers (load bearers on head and cart pullers) from markets and rail stations of different area of West Bengal, India.

This study was performed following the ethical guidelines for biomedical research on human participants as directed by ICMR, Govt. of India and due permission was taken from the Institutional Ethical Committee (IEC) for research on human participants - of University of Calcutta.

\section{The inclusion criteria were}


1. Uninterrupted work experience for minimum 5 years.

2. Not taking of any types of regular medicine.

3. Subjects age range from 25 to 38 years.

\section{The exclusion criteria were}

1. Any type of acute diseases.

2. Already exposed to any eye disorders.

3. Not interested to take part in full study tenure.

\section{Research design: -}

1. The height $\&$ weight of all subjects were measured by means of anthropometer \& weighing machine.

2. The Body Mass Index (BMI) \& Ponderal Index (PI) of all subjects were calculated by standard formula. BMI is used to measure the degree of adiposity and PI is used for degree of growth restriction.

3. Blood pressure, Heart Rate \& Peak Expiratory Flow Rate (PEFR) were measured by sphygmomanometer, stopwatch and peak flow meter respectively.

4. Recommended weight limit \& Lifting Index were measured by NIOSH equation.

\section{LC (51) x HM x VM x DM $\times$ AM $x$ FM $\times$ CM = RWL}

1. $\mathrm{HM}=$ Horizontal location of the object relative to the body

2. $\quad \mathrm{VM}=$ Vertical location of the object relative to the floor

3. $\mathrm{DM}=$ Distance the object is moved vertically

4. $\mathrm{AM}=$ Asymmetry angle or twisting requirement

5. $\quad F M=$ Frequency and duration of lifting activity

6. $\mathrm{CM}=$ Coupling or quality of the workers grip on the object

7. $\quad$ LC $(51)=$ Load Constant of 51 pounds

Lifting Index (LI): Weight $\div$ RWL = LI

Eye pressure was measured by Tonometer.

\section{Statistical Analysis:-}

Statistical analyses were performed using Minitab 16. Quantitative variables were expressed as mean $\pm \mathrm{S}_{\mathrm{D}}$. Paired $\mathbf{t}$ tests were performed to evaluate the overall cumulative weight effecton labors' health. $\mathrm{P}$ values of less than $\mathbf{0 . 0 5}$ were considered to be significant.

\section{Results:-}

Extensive statistical treatment of the data showed mean values of Height, Weight, BMI, PI of Manual Load Bearer of West Bengal in Table 1. Mean Blood Pressure, Heart Rate, PEFR values expressed in resting and post exercise condition are tabulated in Table 2. Recommended Weight Limit, Lifting Index values expressed in origin \& destination \& Job Strain Index are tabulated in Table 3. Stress related Intra-Ocular Pressure of Eyes values are expressed in Table 4.

Table 1:-Demographic presentation of physical parameters of Manual Load Bearer.

\begin{tabular}{|c|c|c|c|c|}
\hline Variables & Mean values & $\mathbf{S}_{\mathbf{D}}$ values & SE values & p- value $(<\mathbf{0 . 0 5})$ \\
\hline Height $(\mathrm{cm})$ & 168.15 & 2.5 & 0.15 & 0.214 \\
\hline Weight $(\mathrm{kg})$ & 58.08 & 1.48 & 0.20 & 0.562 \\
\hline BMI $(\mathrm{kg} / \mathrm{m} 2)$ & 22.77 & 1.77 & 0.13 & 0.235 \\
\hline PI $(\mathrm{kg} / \mathrm{m} 3)$ & 14.67 & 1.04 & 0.075 & 0.364 \\
\hline
\end{tabular}

Table 2:-Demographic presentation of physiological parameters of Manual Load Bearer.

\begin{tabular}{|l|c|c|c|}
\hline \multicolumn{1}{|c|}{ Variables } & Resting Condition & Post-Exercise Condition & p- value(<0.05) \\
\hline Systolic Blood Pressure (mmHg) & $119.16 \pm 2.14$ & $146.12 \pm 2.11$ & $\mathbf{0 . 0 0 3} *$ \\
\hline Diastolic Blood Pressure (mmHg) & $79.08 \pm 1.45$ & $93.6 \pm 2.34$ & $\mathbf{0 . 0 0 5}^{*}$ \\
\hline Heart Rate (b/min) & $84.25 \pm 2.55$ & $120.5 \pm 1.36$ & $\mathbf{0 . 0 0 1}^{*}$ \\
\hline PEFR (lit/min) & $480.56 \pm 2.11$ & $310.89 \pm 2.36$ & $\mathbf{0 . 0 0 3}^{*}$ \\
\hline
\end{tabular}

(mean \pm SD) 
Table 3:-Demographic presentation of Lifting concern parameters of Manual Load Bearer.

\begin{tabular}{|l|c|c|c|c|}
\hline \multicolumn{1}{|c|}{ Variables } & Origin (Mean) & Destination (Mean) & Actual values & p- value $(<\mathbf{0 . 0 5})$ \\
\hline RWL $(\mathrm{Kg})$ & $9.686 \pm 1.68$ & $11.585 \pm 1.13$ & $\mathbf{5 8 . 1 7}$ & $\mathbf{0 . 0 0 2}$ \\
\hline Lifting Index & $6.1357 \pm 1.54$ & $4.69 \pm 2.1$ & $\mathbf{1}$ & $\mathbf{0 . 0 4 5}^{*}$ \\
\hline JSI & \multicolumn{2}{|c|}{$29.3 \pm 1.91$} & $\mathbf{7}$ & $\mathbf{0 . 0 0 6}^{*}$ \\
\hline
\end{tabular}

(mean \pm SD)(RWL actual value suggest the average weightlifting in worktime by individual)

Table 4:-Representation of Intraocular Pressure (IOP) of right eye (RE) and left eye (LE) of Manual Load Bearer.

\begin{tabular}{|c|c|c|c|c|c|}
\hline \multirow{2}{*}{ Parameters } & \multicolumn{2}{|c|}{ MLB } & \multicolumn{2}{|c|}{ Cart puller } & \multirow{2}{*}{$p$ - value $(<0.05)$} \\
\hline & Mean & $\mathbf{S}_{\mathrm{D}}$ & Mean & $\mathbf{S}_{\mathrm{D}}$ & \\
\hline IOPRE $(\mathrm{mmHg})$ & 23.00 & 2.97 & 11.000 & 1.265 & 0.004* \\
\hline IOPLE $(\mathrm{mmHg})$ & 23.50 & 3.02 & 11.33 & 1.366 & $0.02 *$ \\
\hline
\end{tabular}

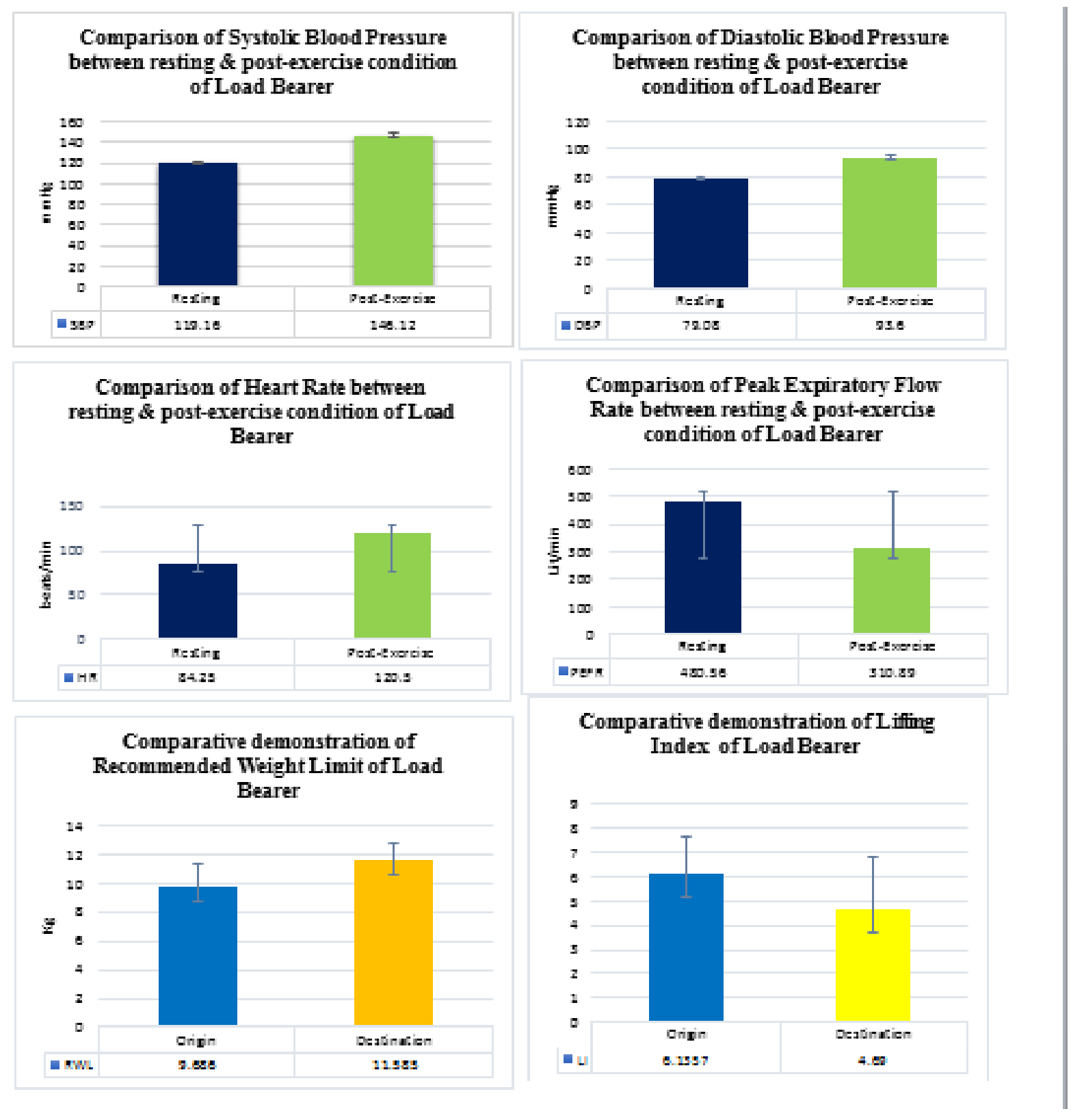


Representation of Scatter graph between Job Strain

\section{Comparative demonstration of Intra-} Occular Pressure on Right Eyes of Load Bearer \& Cart-Pullar

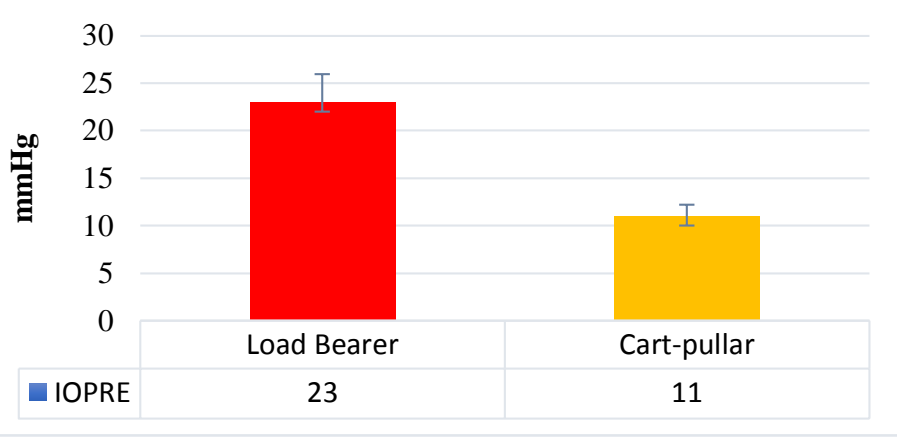

Index \& Lifting Index values

\section{Comparative demonstration of Intra-Occular Pressure on Left Eyes of Load Bearer \& Cart-Pullar}

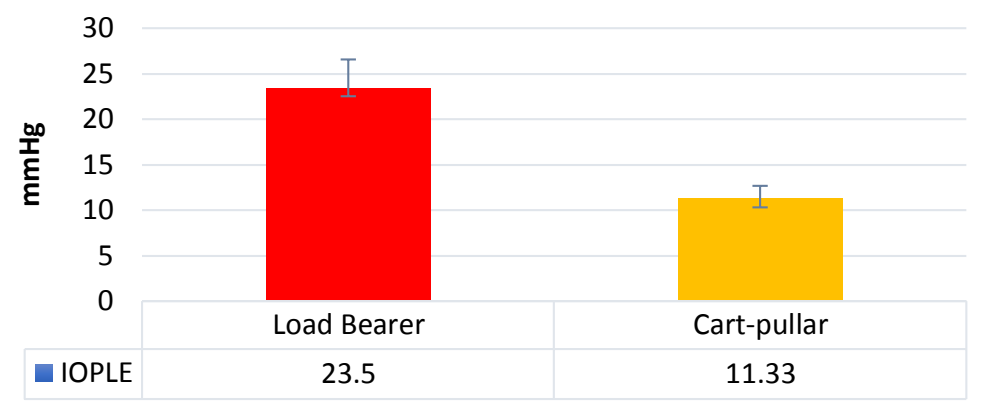

\section{Discussion: -}

The present study investigated occupational risk and abatement measure of hazards amongst load bearers of Kolkata. Manual handling by laborers in the market area belong to unorganized sectors, which is related to many occupational health hazards. These load bearers (subjects) belong to low socioeconomic status. They are daily wage earners. Laborers are compelled to accept extremely strenuous job for their livelihood. The job of the Load bearer includes manual material handling, overloaded material carrying, repetitive exposure to awkward positioning etc. Each sector of these job profiles is found to include additional burden amongst laborers for obvious reasons.

About $79 \%$ of male person in India are labourers. It was found that the workers had to work 10-12 hours daily. Very often it happened that they worked day and night to finish work due to time constraint. The tasks of the material handling are completed within a cycle time of $10-12 \mathrm{~min} \pm 5$ minutes. Thus, they are bound to complete about 6 such cycles in an hour approximately.

In this particular study it is clear that, Systolic blood pressure, Diastolic blood pressure, Heart rate and PEFR shows significantly higher value in post exercise condition than resting and it recovers after 5-6 cycles. Work recovery cycles make use of proper rest in activity to reduce or eliminate worker exposure to ergonomic risk factors. The use of recovery cycles aids in the prevention of musculoskeletal injuries related to static or awkward posture and 
repetitive tasks by providing relief and rest to working muscle groups. When a muscle group becomes fatigued the risk of injury increases. The specific recovery time needed for a particular task is fixed or confined. If labourers are made to rotate between different jobs, alternating between physical and non-physical tasks, or made to perform tasks that utilize different muscle groups, then work recovery time may be improved. ${ }^{[6]}$

The results of RWL, LI and Job Strain Index (JSI) vividly showed that recommended weight limit is only theoretically used for subjects concerned, as all the subjects are carrying significantly higher load than that of RWL, which is detrimental to their health altogether. Moreover, calculated JSI showed significantly higher values than NIOSH recommended value of seven, with a view of reduction of occupational hazards. But in this study the average JSI value is beyond seven by miles, which is indicative of the dimension of agony and pain they are suffering from.

As per NIOSH recommendation, when Lifting Index is less than 1, there is nominal risk of MSD of the particular subjects. But LI value of 1 or more suggest that, there are occupational hazards in that particular work and as the LI increases, risk factor of that work increases in direct proportion with the increment. LI is to provide a relative estimate of the level of physical stress and MSD related risk associated with the manual lifting tasks.

Many literature suggest that, psychological and physical stress can affect intra-ocular pressure of both eyes. Some literature stated that, after 48 hours of withdrawal of strenuous exercise, IOP decreases and returnes to baseline level. In this study, IOP is measured in resting condition and after 48 hours of withdrawal of strenuous exercise of two groups, load bearers (on head) and cart-pullers. Interestingly, it is found that, the load bearers have much higher level of IOP in both eyes than cart pullers. This indicates that repetitive exposure to excessively strenuous job damages their optic nerve and may result in prevalence of glaucoma and permanent vision damage.

JSI and LI thereby are found to be the most properly suited indicator for early risk assessment of the concerned subjects. As scatter graph suggest, Job Strain Index and Lifting Index are directly proportionate to each other and both are dependent upon RWL.

\section{Conclusion:-}

It appears from the study that load bearers are enormously stressed due to carriage of huge amount of load (not ergonomically recognized by NIOSH) for longer time and with abnormal body posture. Thus, the Lifting Index shows a significant correlation with Job Strain Index. Repetitive exposure to strenuous job, not only affects their body parts, but also affects their eye pressure.

The use of elastic back supports (belts) significantly affected spine kinetics. While lifting small and large boxes on a sagittal plane, motions were reduced. Flexion of knees and hip increased while wearing back supports and performing lifts of both small and large boxes. Wearing an elastic back support while lifting either the large or the small box significantly reduced maximum spine flexion, angular velocity and maximum extension angular velocity. The use of head gear may reduce their intraocular pressure significantly. After lifting a huge load on their head, the load pressure may be reduced if the workers put on a gear.

\section{Acknowledgement:-}

We are indebted to and convey our deepest sense of gratitude and sincere appreciation to all the manual load bearer of market and rail stations.

\section{Reference:-}

1. Triano JJ, Selby NC. Manual material handling to prevent back injury. Spine-health. 2006 Sep:1-3.

2. Wiktorin C, Selin K, Ekenvall L, Kilbom Å, Alfredsson L. Evaluation of perceived and self-reported manual forces exerted in occupational materials handling. Applied Ergonomics. 1996 Aug 1;27(4):231-9.

3. Gerr F, Letz R, Landrigan PJ. Upper-extremity musculoskeletal disorders of occupational origin. Annual review of public health. 1991 May;12(1):543-66.

4. Ajimotokan HA. The effect of coupling repetitive motion Tasks with A manual-stressed work environment.

5. Vieira GM, Oliveira HB, de Andrade DT, Bottaro M, Ritch R. Intraocular pressure variation during weightlifting. Archives of Ophthalmology. 2006 Sep 1;124(9):1251-4.

6. "Work Recovery Cycles" Workplace testinglErgonomics: https://www.workplacetesting.com/definition/1620/workrecovery-cycles 